\title{
Theorising First-generation Students' Successes at a Historically White South African University
}

\section{Mlamuli Nkosingphile Hlatshwayo Kehdinga George Fomunyam}

\begin{abstract}
This article attempts to shift the first-generation literature to not only focus on the marginalised experiences of first-generation students, but to also theorise the successes that these students have experienced in negotiating a historically white higher education institution. To do this, data was generated using semistructured interviews and participants were sampled using snowball sampling and this ensured that the social networks and connections that these students have with one another, were accessed. 32 first generation students were recruited, and in-depth interviews were held with each of the participants, averaging one hour per student. The data or findings indicate that the success of first-generation students largely depends on four key forces - the force of diligence, the force of language, the force of personal attributes, as well as the force of personal relationships. Bourdieu's field theory, capital (social and cultural), and habitus were employment to further make sense of the findings. All these forces play a critical role in ensuring that first-generation students are not only able to negotiate their marginality in a historically white HE, but that they are successful.
\end{abstract}

Keywords: first-generation students, field theory, social capital, cultural capital, habitus

\section{Introduction}

With the advent of the post-apartheid democratic order in 1994, higher education institutions (HEIs) in South Africa have had a significant increase in 
student enrolment from students generally referred to as 'first-generation students' or 'non-traditional' students, that is, students who are the first in their family to formally access higher education (Badat \& Sayed 2014; Cross \& Carpentier 2009; Sennett, Finchilescu, Gibson \& Strauss 2003). These students predominately come from low socio-economic backgrounds, with a significant number of them being at the risk of dropping out (Strydom, Kuh \& Mentz 2010). The increasingly diverse student population in HEIs (both racial and socio-economical), places pressure on the declining resources within this sector (Strydom et al. 2010).

Internationally, the literature on first-generation students tends to focus on a number of factors that can largely be attributed to deficiencies that these students have. Some of the literature focuses on first-generation dropout rates (Tinto 1975); others focus on comparing first-generation students' academic performance with 'traditional' mainstream students (Berkner \& Chavez 1997; Horn \& Nuñez 2000). Some other international literature focuses on first-generations students' persistence in tertiary education, duration of degree attainment, as well as early career entry into the labour markets (Berkner, Horn, Clune \& Carroll 2000; Horn \& Nuñez 2000; Ishitani 2006).

This article argues that higher education literature has largely focused on the challenges that confront first-generation students, and has not sufficiently theorised some of the strategies and approaches that these students have adopted in negotiating their marginality and success in HE. This article attempts to fill this gap by theorising how first-generation Black working class students in a South African historically white institution (HWI) succeed and how they negotiate their marginality.

To make sense of how first-generation students negotiated their way to success, Bourdieu's (1993) theoretical lenses of field, capital and habitus are employed so as to illuminate the various ways in which first-generation students have not only encountered challenges and marginality in HE, but how they have responded to this marginality through the use of their dispositions, networks, connections, and associations in succeeding in the contested field of HE.

\section{Locating the Context}

Higher education institutions in South Africa are profoundly shaped by the history of colonisation and apartheid (Akoojee \& Nkomo 2007; Badat 2008; 
Naidoo 2004). The apartheid regime's production of racialized inequality and white supremacy was extended to institutions of higher learning as academic and intellectual instruments of racialized difference and reinforced the segregation that the regime promoted. This resulted in critical conversations beginning in the1990s, regarding the role of HE in a democratic South Africa, and what these institutions could look like (Akoojee \& Nkomo 2007; Badat 010; 2016). Badat (2008:121) argues that,

In apartheid South Africa, social inequalities of a class, race, gender, institutional, and spatial nature profoundly shaped higher education. Given this, South Africa's new democratic government committed itself in 1994 to transforming higher education as well as the inherited apartheid social and economic structure, and institutionalizing a new social order. Necessarily, the realisation of social equity and redress for historically disadvantaged social groups in higher education, and therefore, the issue of admissions, have also loomed large in policy discourse.

The higher education sector has therefore been engaging both the policy landscape and the enactment of the same in the drive to improve access and throughput. Naidoo (2004) adds that there were three different kinds of universities during the apartheid period in South Africa - the dominant tier, the intermediate tier, and finally the subordinate tier. Firstly, the dominant tier consisted of the English-speaking universities that were established during the colonial period for the benefit of the British English-speaking community. With the introduction of the apartheid laws in 1959, these universities became exclusively available only for white students (Naidoo 2004). These universities were (and largely continue to be) research-intensive, internationally recognised and enjoy massive amounts of resources and research support. It is on one of these institutions that the study is based, while looking at how first generation Black working-class students, whose presence in this institution, goes against the colonial and apartheid purpose of racialized HE segregation, navigate their way to success and how these students have negotiated their belonging and success in such spaces.

Secondly, the intermediary tier consisted predominately of the Afrikaans-speaking universities which were also designated for white students, and set up by the Afrikaans community during the Anglo Boer War (Naidoo 
2004). These institutions became the intellectual, academic, linguistic and political hub for producing and reproducing Afrikaner national identity and the Afrikaner elites who would run the apartheid state and reinforce the National Party's conception of social reality as racialized, segregated and violent. The function of these universities was to act as an Afrikaner alternative to the English colonial liberalism that was seen to be promoted by the universities in the dominant tier. These institutions sought to offer an alternative of Afrikaner repositories of knowledge production and competing knowledge claims, as required and supported by the apartheid regime. In other words, the primary function of these universities was to reinforce the apartheid social order and help maintain at least intellectually, academically and linguistically, the existence of the regime (Davies 1996). This was also seen in the amount of resources that were poured into these universities by the apartheid state.

Finally, in the last group, you had the subordinate tier. These universities were set up for different Black South African ethnic groups. These institutions were characterised (and to some extent, still continue to be) by poor funding, and poor research and infrastructure (Davies 1996; Naidoo 2004).

It was against the above background that the incoming democratic government was confronted with a fragmented and racially stratified HE landscape in South Africa, one characterised by the racial divide between the historically white higher universities and the structurally under-resourced and fragmented Black universities (HBUs) (Akoojee \& Nkomo 2007; Badat 2016; Badat \& Sayed 2014). The Ministry of Education's significant policy document for HE transformation, the 'Education White Paper 3: A Programme for the Transformation of Higher Education' (hereafter referred to as White Paper 3) has, as one of its central goals, the expansion of the HE system through equity and growth (Department of Education 1997). This, according to the policy, was targeted at expanding the HE system in an attempt at ensuring that the demographical representation of the HE student body reflects the national demographics of the country. This includes ensuring that 'any expansion and equity strategy must be on increasing the participation and success rates of black students in general, and of African, Coloured and women students (Department of Education 1997: 15-16).

The expansion of the higher education system, resulted in what has been termed a 'demographic revolution' (Akoojee \& Nkomo 2007) in the Black student enrolment in HEI. For example, between 2010-2015 the African student enrolment in HE increased from 595963 in 2010 to 696320 in 2015, 
indicating a $14.4 \%$ increase. Similarly, Coloured students enrolment increased from 58219 to 62 186, indicating an increase rate of 6.4\% (Council on Higher Education 2017). In the same reporting period, there appears a decline on the HE enrolment rate for White and Indian students. White student enrolment in 2010 was 178 346. It declined to 161739 by 2015, indicating a decline percentage of $10.3 \%$ during this reporting period. Indian student enrolment in 2010 was 54 537, and declined to about 53378 in 2015, indicating a decline of about 2.2\% (Council on Higher Education 2017).

Although the focus has largely been on the proliferating 'demographic revolution' that has characterised HE since the democratic dispensation, there continues to be a call within the South African HE literature for conceptualising access to $\mathrm{HE}$ as only referring to formal, physical access to universities (Bozalek, Garraway \& McKenna 2011; Council on Higher Education 2017; Morrow 1993; 2009). This argument seeks to suggest that although democratising and de-segregating $\mathrm{HE}$ in opening the gates to the historically marginalised communities is important, there similarly needs to be closer attention paid on how the marginalised are also denied access to disciplinary knowledge. This includes looking at the role of HE curriculum, institutional culture(s), space and spatiality, architectural designs and others in perpetuating the marginality of these students and rendering them to the periphery of the HE landscape (Morrow 1993; 1994; 2009; Muller 2014).

This article attempts to address this matter by arguing that HE access has drastically improved numerically in relation to first-generation students, but that there is a gap in the literature in relation to epistemological access, and this offers an opportunity for the theorising of the strategies that firstgeneration students use to negotiate their marginality that enables them to succeed in HE. To theorise this, this article utilises some of Bourdieu's key theoretical concepts to help shed light on some of these strategies, and how they enable first-generation students to thrive in a historically white higher education institution.

\section{Research Design and Methodology}

Maree (2007) argues that the research design is a map drawn by the researcher which indicates what he or she is going to do throughout the research journey, and which steps to follow. This means that this map not only accommodates the information, but it also integrates this information into the existing 
knowledge, thereby helping to produce the final product, that is, the critical findings of the research (Fomunyam 2016b). Fomunyam (2016b) suggests that the research design process tends to focus on the results, while the research methodology focuses on generating these results or the findings through focusing on the methods that are employed in the study. A qualitative case study was used in this article to theorise the successes of first-generation black working-class students on how they negotiated their marginality in a historically white higher education institution.

A case study is defined as a 'an in-depth study of one particular case in which the case may be a person, a school, a group of people, an organisation, a community, an event, a movement, or geographical unit' (Neuman 2010: 40). Cohen, Manion, and Morrison (2013) similarly agree that a case study is often employed within qualitative research. Theorising the successes of first-generation students in a historically white higher education institution could likewise be studied as a case study that seeks to critically interrogate the various ways in which first-generation students negotiate their marginality in HE.

This article employed qualitative research methods of data generation and analysis, located within the interpretivist paradigm. Palys (2008: xxix) suggests that qualitative research is designed to 'explore the human elements of a given topic' in allowing us to see how 'individuals see and experience the world'. This means that qualitative research assumes that individuals play a significant role in the social construction of their own social reality, and that the role of researchers is thus to interpret the various ways in which individuals make sense of their reality. Mack, Woodsong, MacQueen, Guest, and Namey (2005) argue that,

The strength of qualitative research is its ability to provide complex textual descriptions of how people experience a given research issue. It provides information about the 'human' side of an issue - that is, the often-contradictory behaviours, beliefs, opinions, emotions, and relationships of individuals. Qualitative methods are also effective in identifying intangible factors, such as social norms, socioeconomic status, gender roles, ethnicity, and religion, whose role in the research issue may not be readily apparent.

For Mack et al. (2005), the strength of qualitative research lies in its ability to give access into the rich social experiences of people by focusing on 
contradictory behaviours, experiences and beliefs. Qualitative research methods seek to interpret the often complex and contradictory social experiences as experienced, thought of, and reconstructed by the individuals themselves. Operating within the interpretivist paradigm, the central aim of this article is to attempt to understand the complex experiences of firstgeneration Black working class South African students' negotiating marginality which ranges from institutional culture, language, curriculum and access, to success, in a historically white higher education institution. Rather than focusing only on interpreting their success or social experiences, the article goes a step further in looking specifically at the interesting ways in which first-generation students negotiate their marginality, as these enable them to survive the HE terrain. Neuman (2010: 102) suggests that interpretivism focuses on the need to understand social reality and the various ways in which people construct meaning-making in their own settings. The use of qualitative research methods in this article provides the necessary insight into the strategies of first-generation students, as they construct their experiences as well as the strategies they employ in negotiating their entry and academic success in a historically white higher education institution.

In the article, 'first-generation students' refers to the Black working class South African students, who are the first in their family to come to university, and whose parents do not have a post-secondary qualification. Since the interest here is in students who had little access to privileged networks and connections, first-generation students who attended public schools either in the township or rural areas, were sampled rather than those who attended advantaged or private schools. This decision was based on the fact that students who attended privileged schools or highly resourced schools were given the tools and capital with which to navigate the higher education system. They were socially connected. The participants were therefore those who did not have access to 'traditional social networks' that could have possibly been obtained through attending private schooling or other privileged suburban forms of public schooling. 32 participants were recruited using snowball sampling to participate in the study taking into account gender, language and origin (Seidman 2006: 51).

Faugier and Sargeant (1997: 792) argue that snowball techniques are particularly useful for hidden populations, or at least when attempting to research around a sensitive topic. The research on first-generation Black working class students and some of the challenges they face as they navigate 
and negotiate their entry into university, is a sensitive topic as it exposes the socio-economic backgrounds that they come from, and some of the difficulties they have to overcome. Biernacki and Waldorf (1981: 141) similarly suggests that snowball sampling is well-suited for qualitative research of a personal nature, which often requires those who are on the inside, to help locate additional participants for the study. Snowballing made it easy to locate participants who had formed networks and connections with one another, and were aware of their friends who were also first-generation students. For purposes of anonymity, the 32 participants were referenced with numbers from one to thirty-two in no particular order.

Semi-structured interviews were employed in an effort to gain in-depth understanding of the lives and experiences of research participants. Seidman (2006: 9) argues that the use of in-depth interviews helps the researcher understand not only the lived experiences of the other people, but it also enables him or her to understand how those people make meaning of their lives. Semi-structured interviews provided a platform to understand, interpret and theorise first-generation students' strategies in negotiating their entry into and marginality in an elite university. The data generated from these interviews were coded and categorised to form themes. These themes were then used to express the views of the participants of the study. The four themes that emerged from the data were: the force of diligence; the force of language; the force of personal attributes; and the force of relation. These themes informed the analysis of the data and direct quotations from the participants were used to substantiate the themes. By letting the data speak for itself and further analysing it, using some of Bourdieu's key concepts, the researchers ensured that, how the participants succeeded were foreground rather than the theory. The theory was engaged to further theorise the experiences of the students. However, before analysing the data, it is vital to discuss the theoretical framing engaged within the study.

\section{Theoretical Framing: Introducing Bourdieu}

At the heart of Bourdieu's theoretical contributions, have been his commitment to expose $\mathrm{HE}$ as a powerful contributor to maintaining and reproducing social inequality (Bourdieu 1993; Naidoo 2004). This focus has led to a significant theoretical and empirical contributions to our sociological understanding on the relationship between universities and society (Naidoo 2004). Naidoo 
(2004) argues that this overarching focus and commitment have resulted in the introduction of the key conceptual tools of 'field', 'capital' and 'habitus'. These concepts relate with and function with one another. In this article, all three conceptual lenses are engaged to theorise the experiences of firstgeneration Black working class students and how they negotiate their marginality in a historically white higher education institution. Before critically discussing the notion of capital (cultural and social), it is important to first outline field because for Bourdieu, the logic of capital operates within the domain of a field (Bourdieu 1993; Naidoo 2004; Shawa 2015).

Drawing on Weber's sociology of religion, Bourdieu conceptualises society as differentiated into a number of semi-autonomous fields (such as the fields of economics, religion, cultural production and others) which are all governed by their own 'rules of the game', with their own economies of exchange, rewards and sanction systems (Benson 1999; Bourdieu \& Johnson 1993). Bourdieu and Wacquant (1974:493) conceive of a field as a "network or configuration, or of objective relations between positions ... these positions are objectively defined in their existence and in the determinations they impose upon their occupants, agents or institutions ... as well as their objective relations to other positions'. In other words, a field can be said to refer to a 'structured space of positions in which the positions and their interactions are determined by the distribution of different kinds of resources or capitals' (Ihlen 2005: 493). A field could therefore also be understood as a space in which people compete for resources with one another (Shawa 2015). This field is 'structuring' because of the manner in which it shapes the actions and choices of those involved, and 'structured' precisely because it is not random or arbitrary. These binaries and oppositions could be said to be reflections and refractions of the overall class divisions in society, as these are seen between the dominant and the dominated, and also the split within the dominant class, between the dominant economic and political power on the one hand, and the dominated cultural power on the other hand (Benson 1999: 464). This means that society is structured around basic oppositions between the 'economic' and 'cultural power', with the latter being regarded to be weaker, but as suggested by Weber, influential to the extent that it legitimates and masks economic wealth.

Using Bourdieu's concept of the field therefore enables the conceptualisation of a historically white higher education institution as a field that compromises of competing actors who have oppositional interests, and all 
competing for symbolic resources. This means that a historically white higher education institution could be conceived of as a relatively autonomous sphere of activities that operates in respect of its own rules and logic (Benson 1999; Giloi 2015; Maton 2013).

As mentioned above, a field comprises of agents who are relationally positioned and who attempt to maximise their position in the field in the struggle over resources (that is, capital) that confer status and authority (Arbee 2012: 37-38). This means that in the field, there is economic, cultural and social capital. Economic capital refers to money, that is, economic resources that one has access to and possesses (Bourdieu 2011). Cultural capital for Bourdieu, exists in three key forms - firstly, it exists in the embodied state, that is, the personal dispositions, habits, tastes, and others. Secondly, it exists through cultural goods, such as books, theories, music and others that one listens to, consumes and continues to accept and legitimate. Thirdly, cultural capital exists through the institutionalised state, that is, the schooling, qualifications, associations and others, that confer cultural capital and belonging in the field (Bourdieu 2011). Social capital refers to the 'aggregate of the actual or potential resources which are linked to possession of a durable network of more or less institutionalized relationships of mutual acquaintance and recognition' (Bourdieu 2011: 83). This is seen in how social capital refers to the networks, connections and associations, both formal and informal, an agent has and belongs to. It should be emphasised that in the Bourdieuan sense, social capital is only capital if an agent not only has access to the networks and connections, but can actually withdraw from them (Bourdieu 2011; Bourdieu \& Johnson 1993; Putnam 1995; 2000). Simply put, knowing someone alone may constitute the social, but not the capital. Social capital denotes the ability to withdraw from the connection through the ability to gain something whether it is information, employment, advice or any 'withdrawal' that may be required.

The relations between the agents and their contestations over the resources give the structure of the field. Both the type of capital (that is, economic/ cultural/ social) together with the amount of capital are significant for conferring status within the field. This means that it is not how much capital you have in the field, but rather whether you have the right type of capital (Arbee 2012). Thus the struggles in the field that first-generation students find themselves in and need to negotiate are not only about the amassing of more capital, but also about the type of capital that should be considered as the 
'dominant measure of achievement' in the field (Maton 2005).

Habitus can be understood as 'the semi-conscious dispositions that people, particularly in their early lives, acquire through social/ material interaction with their habitat and through the social relations in their part of the social field' (Fairclough, Jessop \& Sayer 2002: 9). Bourdieu defines habitus as a 'set of assumptions, habits, taken-for-granted ideas and ways of being that are vehicles through which agents engage with, understand and move on through the world' (Bourdieu 1977 in Bebbington 2007; 155-156). This means that for Bourdieu, habitus explains our beliefs, thoughts, tastes and interests that tend to influence our understanding of the world. This is seen in how habitus is formed primarily by socialisation through family, schooling, culture as well as the milieu of education (Bourdieu 2011; Bourdieu \& Johnson 1993; Bourdieu \& Wacquant 1974).

In relation to this article, habitus offers an opportunity to look at the dispositions, beliefs, thoughts and behaviour of first-generation Black working class students in the historically white higher education field, and how they use their dispositions, tastes, values, beliefs and others to negotiate their marginality and succeed in HE. The outlined conceptual and theoretical tools from Bourdieu, will be employed in the study, to theorise the successes of firstgeneration students as they navigate the contested field of HE.

\section{Data Analysis and Discussion}

As mentioned above, four themes emerged for the coding and the categorisation of the data. These themes were the force of diligence; the force of language; the force of personal attributes; and the force of relationship. These themes are foregrounded in this section of the paper and direct quotations from the participants are used to substantiate and explain them. Both the theoretical lens and the literature are used to further explain, justify and make meaning of the findings of the study.

\section{The Force of Diligence}

Powell (2017) defines diligence as working hard and doing the best job that you can possibly do. A student is set to be diligent when he or she takes special care to do things step by step, think and move carefully to make sure things turn out right. It is being industrious, giving all you have to give to whatever 
you do. Galla et al. (2014: 316) adds that academic diligence can be understood as 'working assiduously on academic tasks which are beneficial in the longrun but tedious in the moment, especially in comparison to more enjoyable, less effortful diversions'. For a student to be seen as diligent, he or she must be committed to rigorous academic engagements and in the case of first generation students, engagements that would grant and improve their access to the curriculum as well as help them negotiate the marginality evident in the landscape in which they find themselves. Galla et al. (2014) add that academic diligence is a domain-specific facet of self-control, which refers more broadly to the regulation of thoughts, emotions, and behaviours in the face of momentary temptations and distractions to focus on navigating the bogus higher education setting. The importance of diligence to success in and beyond the classroom cannot be over emphasised and it has been proven or affirmed in several longitudinal studies that academic diligence directly contributes to student success (Galla et al. 2014; Powell 2017). The participants of the study attested to the fact that being diligent was key to their success. Supporting this, participant one stated that,

In my first test in Zoo I got like 13\%! Do you know how painful it is when you know that in high school you did so well and you come here and your first test you get $13 \%$. Because you didn't hear a thing. They were talking about dinosaurs, people who are from backgrounds where you are exposed to world war stuff then you would get it. I didn't get it. I went to the Physics one because I didn't hear anything. I went to ADPs [academic development programmes], I still didn't get a thing ...I went to people, to that guy the mentor. I went to study groups, I went to people who had question papers, past question papers. I asked if they had past question papers. I went out of my way to get standard. And I'm not going to leave now because of my schoolwork ...I have to do anything to get to where I wanna be. So I went to ADPs and stuff that's what happened. The workload was increased because I did not have a laptop. I didn't have the phone that can chat, I had that green screen thing, it had cello tape around it. I was like oh, everything that I do it should be school centred. It was the first time that I actually saw like a microscope, cylinder, and all those lab things. But I had to go the extra mile every step of the way to succeed. 
Lee, Dunlap, and Edwards (2014) argue that the lack of cultural capital would inhibit an individual's ability to progress in certain societies or systems. This is supported by Acar (2011) who argues that greater amounts of social and cultural capital (which is characterised by the educational qualification of parents, the presence of two parents at home and others) and intergenerational closure and/ or educational experience lead to lower incidence of dropping out of school and better academic performance. Being a first-generation student therefore and lacking in social and cultural capital, ensured that participant one had to resort to diligence to break through these barriers and navigate the HE landscape.

Bourdieu (1997) sees different forms of capital as mutually constitutive in that economic capital affords the time and resources for investment in the development of children's cultural capital, which is associated with future educational and occupational success and, in turn, contributes to the accumulation of economic capital. Educational success is also associated with greater social capital in that one's social network becomes broader, more influential, and more conducive to opportunity and further enhancement of one's other capital stocks. Another participant illustrated this perfectly by stating that,

Yoh when I arrived, for me I found out that there was too much! Too much way too much work here at the university for full-time students. Like you have to work every day, this University hayi you have to work every day, every hour work work work. Like you'll spend five days and still getting the results that you're not satisfied with. Like for me academically, like the first two weeks they were going very badly cause I remember I wrote the test and I was the lowest in class and then the lecturer called me and asked me what happened. And I was like Hhayi [no] I'm going to quit now. Because I'm not used to when I fail and someone calls me out of the rest, so I felt like I'm an outlier now like I don't fit in. So ah for me it wasn't easy it wasn't easy at all. All and one other problem, you know growing up without a computer here you have to type something. You don't use like handwriting so you have to type most of the work. So ya, that was hard because we didn't use computers at high school. So, when you come here, they give you student number ...they don't explain, they just give you that paper. You don't even know like what I am going to do with this. I'm 
like you don't even know where to go for Internet and stuff until they teach you in res [residence]. They don't like tell you everything. So yeah technology I would say, it was a restriction for us. To succeed, you had to go the extra mile to work on Saturday and Sundays. It was work, work, work.

Another participant support this by pointing out that

Yeah academically we formed like group studies me and this guy not specifically group studies, me and this guy since we saw that we were lacking .... And this guy said okay you know what we can do this to study me and you everyday practice. Revise whatever that we did in class. And share ideas, and if we don't understand since we are lucky we had tutors, we go and ask tutors...Then we coped, cause when I don't know a question I always go to him. We wouldn't mind studying till 1 o'clock in the morning. I would go to him... man can you explain this to me. He will explain. If he doesn't understand something he would come to me... And if I don't know, we'll go to a mentor and try and then suddenly we find like a solution to the problem or whatever .... That's why I'm saying me and that guy we related because everything was perfect between me and him. We worked tirelessly together to succeed.

Sullivan (2002) argues that in the education system, success is facilitated by the possession of cultural capital and a higher-class habitus. Students who possess lower-class habitus do not in general possess these traits, so the failure of the majority of these students is inevitable. This explains how class inequalities continue to manifest itself in educational attainment. She adds that success and failure in the education system can also be facilitated by individual credence or gifts (or the lack of them).

Acar (2011: 458) adds to this, and argues that the 'differences in student or academic success can be attributed to different levels of existing social capital which is produced in the networks and connections of families that the school serves ... social capital supports success and education in the form of the disciplinary and academic climate at school, and also the cultural norms and values that motivate students to achieve higher goals'. Since first generation students do not have such networks, they have to engage the force 
of diligence in ensuring access in the field. Thus, in the absence of economic and cultural capital, they resort to the force of diligence and social capital networks to 'make up' this stock and ensure that they navigate and succeed in HE. Talking about developing social capital networks and connections for success through diligence, participant 15 stated that,

We were in study groups. By study groups I do not necessarily mean that people will sit together and study together. What I mean is you are at the library, I am at the library. Me seeing you there sort of also motivates me to study .... I felt like the people in the library had read all the books in the library and I hadn't so I had to catch up so that for me is why I kept on reading stuff. I read and study continuously. By talking to these people once in a while, I learn a lot and know that I must keep studying if I must succeed.

Another participant added that,

I found it [university] very intense. And to an extent that I couldn't, stop work and, I remember this so many times within the first term that I used to just cry and called home and all of that, especially with the pressure is off things like computer science ... but after that I will sit down to study again. So yeah when we go to class I would always be that one who was asking things, like what is these, and people who did IT and have been using it would have an understanding of what it is. So, they will explain to me and I would continue studying.

Bourdieu (2002) argues that habitus is a learned set of preferences or dispositions by which a person orients to the social world. It is a system of durable, transposable, cognitive schemata or structures of perception, conception and action. Habitus is rooted in family upbringing (socialization within the family) and id often conditioned by one's position in the social structure. The lack of vital habitus or the presence of a certain kind of habitus means that first generation students need to go an extra mile to make it in an historically white institution. Their engagement with the higher education landscape and material, needs to be over and above that of other students, for them to succeed. Sullivan (2002), building on Bourdieu's argument on the role of capital as a tool for social (re)production of class and inequality in society, 
similarly argues that the upper class maintains their class position and legitimate this dominant position through the academic system and the constant transfer of economic, social and cultural capital, giving them an 'inherent' and inherited advantage when they get to university. Simply put, the upper and middle class would already have already attended privileged schooling, extra curricula activities, well-resourced sporting activities, church organisations and others, which would constitute the institutionalised states that confer on them, the cultural capital that they need to succeed. This would ensure that these students would have the personal dispositions, habits, tastes and other qualities and resources, needed to navigate the HE terrain. First-generation students, who lack access into these institutionalised and embodied states, are thus forced to construct for themselves, alternative social networks with one another, that they can access and withdraw form in succeeding in HE. Thus, the force of diligence is important in helping us understand the thoughts, values and beliefs as well as the actions that first-generation students engage in, in making sense of their social reality in a historically white HE institution.

\section{The Force of Language}

Language is a critical issue for success in education. Crose (2011) argues that when students of varying language backgrounds come together in a classroom, language barriers are inherent. Language doesn't only affect the ability to learn, but it can also decreases the confidence of students to communicate in the classroom and this eventually leads to poor academic performance (Fomunyam $\&$ Mnisi 2017). Crose (2011) goes further to add that even students who felt they were proficient in the English language stated that at times teaching and learning in the English language becomes problematic especially when the student is not familiar with the accent of the speaker or the pronunciation pattern or even the dialect of English spoken by the teacher. Edgerton and Roberts (2014) add to this, and argues that the habitus, cultural and social capital, include adaptive cultural and social competencies such as familiarity with relevant institutional contexts, processes, and expectations, possession of relevant intellectual and social skills and a more 'strategic conception of agency'. The competences are in-built in and communicated through language especially in the HE landscape where knowledge is ferried predominantly through language. In the field of HE these competencies work in concert to capital's ability to successfully affect student's educational outcomes. 
First generation students lack a grasp of the English language which itself is a component of capital, as well as the related English networks that connects within the higher education sphere, which other students whose parents or siblings have been heavily invested in HE, possess and transfer to them. Edgerton and Roberts (2014) also suggest that cultural capital cannot be divorced from academic/ technical skills or 'ability' because academic competence is largely a social construction, an imposition of evaluative standards by ascendant interests invested in preserving and justifying the means of their ascendance. Without a mastery of language therefore, academic performance is in jeopardy. The findings of the study demonstrated this clearly. To this end, participant 31 stated that:

For me the language barrier was really hard. And on top of that is the workload, but because I'm used to teaching myself, because we didn't have a lot of teachers in school. So, what I did was I took my strategies that I used to use in high school and I applied them here but they didn't work ..., I had to go further than that to get the same kind of reward, that I got to high school .... So I had to go to attend language programs at night .... I also watched a lot of movies in English, I interacted with people who only spoke in English, so that I could only speak with them in English. So that forced me to speak English. That's how I learnt and improved my grades.

Another participant added that:

Where I came from, we speak Xhosa, so you would normally communicate in Xhosa. Suddenly, I'm to express myself in English, which I'm not fluent in. even when I will chill with people, I won't talk that much because I'm afraid if I say something wrong people might laugh at me or something. Yeah even in my class because I was accepted in BComm accounting, if I have question I will not ask in class, I would ask after the lecture.... speaking English all the time that was the most uncomfortable thing cause I was afraid of making mistakes. Then one of the mentors advise me to take the English program. I took it and buried myself into it. I started learning and gaining confidence. Then I started speaking gradually. I also started doing well in class. 
Bourdieu (1990:107) argues that 'I think that, literary and stylistic qualities (language) ... are complex' and expressing thought enshrined in long history of cultural dominance 'can only be said in a complex way ... that reality is not only complex, but also structured ... if you want to hold the world in all its complexity and at the same time order and articulate it ... you have to use heavily articulated sentences'. Language is seen here as structured and as a structuring structure. This means that in HE, languages could be seen as a socio-linguistic structure that constructs, produces and re-produces discourses and knowledge that are predominately transmitted through English. Thus, we suggest that language is the gateway to epistemological access, without which failure is inevitable. For first generation students, to succeed in a historically white South African university, they must engage and master language and use its force to navigate the field for the higher education landscape constitute a field with a range of dynamics.

Bourdieu (2002) further claims that the criteria of university examiners reflect the values of the dominant classes, and that the more vague the demands of the examiners are, the less chance working class pupils will have of adhering to these demands. These show how important the cultural arbitrary is in contributing to class inequalities in educational attainment. Student exams in the higher education sector taken by students to ascertain their performance is nuanced by language and the explicit criteria embedded in it. A mastery of the language of teaching and learning therefore is key to success for first generation students.

Another participant added that,

I think since they say practice makes perfect, I started by practicing ... but when I tried speaking English ... with black people they always laugh at me. So me I found it more comfortable when I spoke with someone who is not Nguni. If I speak to someone who is white they would understand me, but if I speak to black they were just leave. So I try to speak, with this friend of mine who is from my corridor. Yeah we used to talk. Like he was white and I was black but he used to listen at me and understand what was saying. Then okay, then I can speak English. I was like okay I can take my time. So that's how I kept on practicing, I kept on practicing to communicate and kept on improving. 
Morrow (2007:18) argues that epistemological access is key to understanding 'the knowledge that universities distribute'. Since this knowledge is distributed using language, it indicates in this case English, which is largely the medium of teaching and learning. Students need a command of the language to gain access to the knowledge. Furthermore, access to the language constitutes access to part of the knowledge itself, and the capital that the language brings with it. This is supported by Bourdieu (2002) who suggests that language which constitutes part of an individual's habitus is what orients people to world. It is a system of 'cognitive schemata or structures of perception, conception and action' (Bourdieu 2002:27). In this sense, language becomes part of the student's 'socialized subjectivity' conditioned by structural circumstances. This process of shaping the agency and gaining access through rigorous practise becomes perceptual schemes of which ends and means of success are attained in a stratified society like the higher education institution in particular, or South Africa in general. Thus, the force of language plays a significant role in ensuring that first-generation students access the 'languages of legitimation' (Maton 2000) that are disseminated and transmitted in the academy. Thus, epistemological access is not possible without first-generation students knowing, understanding and speaking the language that carries access to the epistemologies of HE.

\section{The Force of Personal Attributes}

Personal attributes are the individual or intrinsic virtues and characteristics that an individual possesses which when tapped into can enhance their academic performance. They can be natural or learned. Burton and Dowling (2009) argue that such characteristics is what distinguishes one student from another and contribute to excellence, challenges or even failure in their academic performance. This means that attributes or certain behavioural patterns of the individual can and do contribute to how he or she performs in the academic setting. This idea is buttressed by Fomunyam and Mnisi (2017) who argue that temperament is a success determinant for students. Since temperament or the student's predisposition is vital to his or her success, it follows that if this force is engaged it can very well contribute to their success. Ulate and Carballo (2010: 43) take this idea further in the findings of their study when they argue that there were certain personality traits which students considered to be most important for them to succeed. Grading these personality traits, 'students 
pointed out that to succeed in their studies, required responsibility and perseverance (45\%); hard work and organization (33\%); motivation (12\%); self-confidence; decision making and punctuality (6\%); and others (4\%); which were all key to success'. This is what Bourdieu (2002) and Walker and Yoon (2017) argue amongst other things, constitute habitus. The individual's predispositions or attributes and embodiments work within a lived field to produce specific kinds of results (success). This is because the field of HE is not docile or innocent but contributes to the overall workings or happenings within the context, and in this case, a historically white institution.

The participants therefore believed that their individual predispositions contributed directly or indirectly to their success in the institution. Building on this, one of the participants pointed out that,

maintaining a positive attitude was key for me. I was very positive when I came to this university. Very, very positive in terms of what I could accomplish academically. So no matter the challenges that came over time I remained positive and believed I could make.

Another participant added that

my faith was what ensure my success. In Soweto, where I come from, we go to church every Sunday. So I learnt that with God everything was possible. So when I came here I was invited to one of the churches. It became my place. They encouraged me and I grew in faith. As I was growing, my performance was also improving.

Building on this experience, another participant added that,

... when I came here, is join this church .... It was not far from my Res [residence] it just convenient [laughs]. It was where I felt comfortable because the way they preach the word it's to accommodate. They are not changing what in the bible says but it's to accommodate the fact that we are students. So, through faith I understood I couldn't fail, I had to pass.

Other participants felt that being responsible and dedicated were key to their success. One of them added to this pointing out that, 
I am a very dedicated person, coming from a school where there was nothing. Few teachers and no resources. You learn if you want to (laughs). So, I learnt to never give up and to be responsible. I also had to take care of my younger sister huh. She is yoh (breathes). You need to be patient with her. Because I was the older one at home, I had to be responsible for her and face my studies same time. So when I came here it was not easy. But that thing in me made me not to give up but to keep going.

Bourdieu (1990: 77) argues that 'habitus, as a system of dispositions to a certain practice, is an objective basis for regular modes of behaviour, and thus for the regularity of modes of practice, and if practices can be predicted ... agents who are equipped with it will behave in a certain way in certain circumstances'. Faced with diverse challenges, the individual's habitus necessitates or makes way for the same to keep going as usual until the desired results are attained. Bourdieu further argues that despite the fact that these implicit tendencies to behave in certain ways are possessed by all, there are no explicit rules or principles that dictate behaviour. Rather 'the habitus goes hand in hand with vagueness and indeterminacy'. This means that habitus no matter how similar, would make different people behave differently as well as produce different results for different people. Since there are no explicit rules for behaving to achieve success, individuals behave in accordance to their predispositions to produce certain kinds of results (success). This is expanded on by Reay (2004) who argues that habitus is multi-layered, with more general notions of habitus at the level of society and more complex, differentiated notions at the level of the individual. A person's individual history is constitutive of habitus, but so also, is the whole collective history of family and class that the individual is a member of. As such, the disadvantageous backgrounds or schools from where these students come from constitute part of their habitus and form a kind of system of cultural capital, on which they can draw from, to fight their challenges when they arise in the course of their studies.

Taking this further, another participant added that,

I am the first one in my family to ever pass matric. So even to pass matric I needed a lot of motivation but there was not body to give me. You know it was hard. Then started motivating myself gradually. 
When I am discouraged, I would sing. Singing made me happy. So as sing I would gradually forget what was disturbing and be motivated to study again. So I use songs to motivate myself. Like praise songs from my place. I would sing about my family and my forefathers. Then I would gain courage and know that if they could then I can.

Reay (2004) argues that the habitus acquired in or through the family is at the basis of the structuring of school experiences. As such, though the habitus is or might be a product of early childhood experiences, and in particular socialization within the family, it is continually re-structured by the individual's encounters with the outside world. University education in particular, acts to harness 'a cultured habitus' which determines the practices or actions of the individual. Warwick, McCray and Board (2017) adds that Bourdieu claims that 'social reality exists twice - in the field, the environment and people around us and habitus, as well as the reality in our minds and bodies'. These two realities work together to produce and individual reality, and in this context, success or failure in this case - which is dependent on the two realities. For Bourdieu (1990: 116), habitus is the product of social conditionings and history and it is constantly being transformed 'either in a direction that reinforces it, when embodied structures of expectation encounter structures of objective chances in harmony with these expectations, or in a direction that transforms it'. This has the capacity to produce success or failure under certain circumstances. These circumstances are subjectively experienced and perceived in nature.

According to Edgerton and Roberts (2014) the key issue here therefore is the degree of habitus - field congruence. If the dispositions of habitus align with the circumstances within a particular field (higher education), change is unlikely to happen. However, if the dispositions align less or fails to align, some degree of disruption is inevitable and success (or lack of it) within that field will be the result. This success (or lack of it) would be the result of the level of change in or within the habitus. Habitus and field therefore can either align to produce failure, or no change in certain circumstances, or fail to align and so create either disruption or success. This means that for first-generation students, their habitus is socially construed through their socialisation, critical awareness of their marginality as well as the burden that comes with the 'firstgeneration' status. This is seen in how they motivate, inspire and remind themselves of where they come from in order to be more diligent, forceful, and 
innovative in negotiating their marginality and ensuring that they use their personality and attributes to better perform academically.

\section{The Force of Relationships}

Relationships constitute the core of learning and success in HE and this is because the process of knowledge construction in higher education is primarily facilitated through relationships. This is supported by Kuh, Cruce, Shoup, Kinzie, and Gonyea (2008) who see relationships as a psychological process, which constitutes attention, interest, investment, and effort in the process of learning. The partnerships and associations of how students form and re-form relationships, constitute the relationships within the higher education landscape and contribute to their success. These relationships constitute part of the capital of the students, especially because they possess a wealth of material and immaterial substance which the student can access and actually draw from. Conner (2016) adds that relationships are key to ensuring students' success and sustained academic engagements. This means that the kind of relationship a student engages in, determines what his or her attention is focused on and whether he or she ultimately succeeds or fails. As mentioned before, Bourdieu (1997)'s capital (that is, economic, cultural and social) all have a link with relationships, be it relationships with people, an institution or environment, and culture. He adds that capital is mutually constitutive and offers the space, time and resources for investment or withdrawal for some form of profiting. This withdrawal can be used to academically succeed, especially because the students get the opportunity to draw on all these sources and continuously improve themselves.

This was the case with a significant number of participants in this study. They believe that the relationships they are engaged in, greatly contribute to their success. Most of them pointed out that they have relationships at different levels. Creating special bonds with new friends, having a working relationship with mentors, joining study groups, academic development programmes amongst other things, all provide opportunities for self-improvement. And, all these relationships ensured that they triumph at the end. Elucidating further, one of the participants pointed out that,

Tango (pseudo name) was in my high school, but he two years ahead of me. He was in the debate team, that's how I know him. I think also 
in the SRC, like for my school and stuff. He's the most talkative person... he will talk forever. When he saw me here, he told me, the things that I should expect from the university, and that things that I should avoid, and the things that I should do. He also informed me of how the university works... you're on your own here. You better know what you here for, and also learn to balance everything in your life, your social life in your academic life. Cause that's a very important thing. And make sure that you, you don't change who you are, because you want to blend into the life of other people. That's what he told me. He was always there advising me and making sure I don't fail and if I do, he would tell me what to do. Yeah that's how I coped.

Another participant talks about the Big Sister programme in her residency, and the role it played for her:

Big sister programme was an initiative by the house committee to get the girls into integrate because I think we as first years were too much and we didn't get along with the older girls and so the house com [committee] was like we can't deal with our own issues and like also try and fit in. So how can we help each other to fit in. So I think that they realized that then they gave us big sisters to advise us basically on everything and kinda keep tabs on you and make sure you okay. We got randomly selected, but if you did want a specific person maybe according to degree or where they from then you could choose a person and yeah it kind of went the whole year. We had picnics and we had to have sister day where everyone came and we had a picnic so people could talk to the older ones and it wasn't just about first years but about trying to survive together. So together we encouraged one another to succeed and we have been improving since then.

The place of relationships cannot be over emphasised especially with regard to first generation students who lack a reasonable mass of capital, be it in whatever form. Combining their capital together, gave every one of them a bigger toolbox to work with, or a larger bank from which they can draw to deal with whatever challenges they have. Fomunyam (2016a) argues that relationships are key to student success in most of their engagements in the 
academic milieu. This is essentially because relationships are central to teaching and learning. Knowledge construction is based on those relationships. For the student to construct worthwhile knowledge, there is need for withdrawal from another individual, group or institution whose capital is different from theirs, so as to facilitate the disruption of marginality and academic success. Walker and Yoon (2017: 407) argued that social capital was of utmost importance to students because of the

relationships developed with supervisors and peers, as well as existing relationships. Social capital acquired during the programme seemed particularly important .... Interestingly, a large majority of respondents had a good working relationship with their supervisor with $83 \%$ of survey respondents reporting a positive relationship .... The social life of students in the department varied, and those who relayed having "hung out" socially with their professors as students were now successful academics.

Navigating their way through the academic ladder was based on the relationships they developed with both their peers and supervisors.

Edgerton and Roberts (2014) says that cultural capital can be seen as both technical and social-behavioural skills which are synergistic determinants of the individual's capacity to comply with prevailing circumstances. The combination of cultural capital through relationships brings about microinteractional processes whereby individuals strategically use these skills, knowledge and competence to enhance their standards or meet institutionalized standards of evaluation. Since assessment for success is based on institutionalized standards, students become able to draw from the cultural capital. Relationships therefore become the basis for the construction of capital which the student subsequently draws on when needed. Thus, personal relationships are at the heart of the argument in this aticle. First-generation students have used social capital networks and connections in navigating the HE landscape, and ensure that they succeed in a historically white university. This is seen in how friends, religious groups, a favourite lecturer, mentors, and as mentioned earlier, residential programmes such as the Big Sister programmes, all could be seen as Bourdieu's social capital networks that ensure that these students are able to 'make up' the absence of economic and cultural capital. 
Furthermore, Bourdieu's argument that the forms of capital not only influence one another, but also how they actually produce each other, was also apparent in the data. Because of the quality of a student's relationship with a lecturer (social capital), they were recommended for a holiday part time job to make extra money (economic capital). This opportunity was used to network with other people, access different social groups, buy the books they needed and begin to be active in the university community (cultural capital). These intricate and at times complex relationships reveal to us, the different and interesting ways in which first-generation students negotiate their marginality and succeed in a historically white university.

\section{Conclusion}

This article argues that first-generation students' literature is replete with students' marginality, throughput and retention rates, adjustment and other challenges in HE. But this literature fails to theorise the complex ways in which first-generation Black working class South Africans students negotiate this marginality and succeed in a historically white HE institution. Bourdieu's theoretical lenses of field theory, capital (both social and cultural) and habitus were used to give meaning to the experiences of first-generations student at a historically white university as a contested terrain in HE, with actors who have access to economic, cultural and the right kind of habitus, more likely to succeed in HE. From the data generated, four key forces were identified that helped explain first-generation student successes - these were the force of diligence; the force of language; the force of personal attributes; and finally, the force of relationships.

These four themes provided insight on how students negotiate marginality and succeed in the higher education landscape. From the findings discussed and analysed above, this article concludes with four critical recommendations that can drive first generation black students' success in historically white institutions.

Firstly, universities should strengthen programmes like Academic Development Programmes, Access programmes (also called Foundation Programmes) as these are actual spaces for first-generations black students to know, understand and access other first-generation students and other wellresourced networks and connections that allow them to negotiate their marginality. 
Secondly, a university's official offices that offer assistance to students, in particular career centres, counselling centres, student affairs offices, residence office and others, should develop programmes targeted at enabling first-generation students to enhance their 'locus of control'. This will help student know and understand that they can play a critical role in negotiating their marginality in a historically white university.

Thirdly, integration/ induction programmes at university should be targeted specifically at first-generation students. This would empower them to overcome distress, pressure, depressions and existential questions of belonging regarding whether they should not immediately de-register. Such kinds of programmes can help first-generation students know and understand that they belong in HE, and can give them the much-needed tools to navigate feelings of social dislocation and non-belonging.

Finally, there is a need to re-visit some of the literacy programmes in South Africa HE. In order to help ensure that first-generation students have epistemological access to the knowledge goods of the university, it is imperative for literacy programmes to assist first-generation students to master and build up the academic, social and linguistic capabilities that are required in HE.

\section{References}

Acar, E. 2011. Effects of Social Capital on Academic Success: A Narrative Synthesis. Educational Research and Reviews 6,6: 456.

Akoojee, S., \& Nkomo, M. 2007. Access and Quality in South African Higher Education: The Twin Challenges of Transformation. South African Journal of Higher Education 21,3: 385 - 399.

https://doi.org/10.4314/sajhe.v21i3.25712

Arbee, A. 2012. Knowledge and Knowers in the Discipline of Marketing at the University of KwaZulu-Natal. PhD, University of KwaZulu-Natal, Durban.

Badat, S. 2008. Redressing the Colonial/ Apartheid Legacy: Social Equity, Redress and Higher Education Admissions in Democratic South Africa. Paper presented at the Conference on Affirmative Action in Higher Education in India, the United States and South Africa. New Delhi, India. Badat, S. 2010. The Challenges of Transformation in Higher Education and 
First Generation Students' Successes at a Historically White University

Training Institutions in South Africa. Development Bank of Southern Africa 8.

Badat, S. 2016. Deciphering the Meanings, and Explaining the South African Higher Education Student Protests of 2015 - 2016. Pax Academica 1: 71106.

Badat, S. \& Y. Sayed 2014. Post-1994 South African Education: The Challenge of Social Justice. The ANNALS of the American Academy of Political and Social Science 652,1: 127 - 148.

https://doi.org/10.1177/0002716213511188

Benson, R. 1999. Field Theory in Comparative Context: A New Paradigm for Media Studies. Theory and Society 28,3: 463 - 498.

https://doi.org/10.1023/A:1006982529917

Berkner, L. \& L. Chavez 1997. Access to Postsecondary Education for the 1992 High School Graduates. Postsecondary Education Descriptive Analysis Reports. Statistical Analysis Report: ERIC.

Berkner, L., L. Horn, M. Clune \& C.D. Carroll 2000. Descriptive Summary of 1995 - 1996 Beginning Postsecondary Students: Three Years Later. Washington, DC: National Center for Educational Statistics (NCES 2000154).

Biernacki, P. \& D. Waldorf 1981. Snowball Sampling: Problems and Techniques of Chain Referral Sampling. Sociological Methods \& Research10,2: 141 - 163. https://doi.org/10.1177/004912418101000205

Bourdieu, P. 1990. In Other Words. Cambridge: Polity Press.

Bourdieu, P. \& R. Johnson 1993. The Field of Cultural Production: Essays on Art and Literature. Columbia University Press.

Bourdieu, P. 1997. Outline of a Theory of Practice. Cambridge: CUP.

Bourdieu, P. 2002. Habitus. In Hillier, J. \& E. Rooksby (eds.): Habitus: A Sense of Place. Burlington, VT: Ashgate.

Bourdieu, P. 2011. The Forms of Sapital (1986). Cultural Theory: An Anthology 1: 81 - 93.

Bourdieu, P. \& J.L. Wacquant 1974. 1992. An Invitation to Reflexive Sociology. Cambridge: Polity.

Bozalek, V., J. Garraway \& S. McKenna 2011. Case Studies of Epistemological Access in Foundation/ Extended Curriculum Programme Studies in South Africa. Cape Town.

Burton, L.J. \& D.G. Dowling 2009. Key Factors that Influence Engineering Students' Academic Auccess: A Longitudinal Study. Paper presented at 
he Proceedings of the Research in Engineering Education Symposium (REES 2009).

Cohen, L., L. Manion \& K. Morrison 2013. Research Methods in Education: London \& New York: Routledge.

Conner, T. 2016. Relationships: The Key to Student Engagement. International Journal of Education and Learning 5,1: 13 - 22.

https://doi.org/10.14257/ijel.2016.5.1.02

Council on Higehr Education 2017. VitalStats Public Higher Education 2015. Council on Higher Education 134.

Crose, B. 2011. Internationalization of the Higher Education Classroom: Strategies to Facilitate Intercultural Learning and Academic Success. International Journal of Teaching and Learning in Higher Education 23,3: 388 - 395 .

Cross, M. \& C. Carpentier 2009. 'New students' in South African Higher Education: Institutional Culture, Student Performance and the Challenge of Democratisation. Perspectives in Education 27,1: 6 - 18.

Davies, J. 1996. The State and the South African University System under Apartheid. Comparative Education 32,3: 319 - 332.

https://doi.org/10.1080/03050069628740

Department of Education 1997. Education White Paper 3: A Programme for the Transformation of Higher Education. Pretoria: Department of Education. Available at:

http://www.che.ac.za/sites/default/files/publications/White_Paper3.pdf.

Edgerton, J. D. \& L.W. Roberts 2014. Cultural Capital or Habitus? Bourdieu and Beyond in the Explanation of Enduring Educational Inequality. Theory and Research in Education 12,2: 193 - 220.

https://doi.org/10.1177/1477878514530231

Fairclough, N., B. Jessop \& A. Sayer 2002. Critical Realism and Semiosis. Alethia 5,1: 2 - 10. https://doi.org/10.1558/aleth.v5i1.2

Faugier, J. \& M. Sargeant 1997. Sampling Hard to Reach Populations. Journal of Advanced Nursing 26,4: 790 - 797. https://doi.org/10.1046/j.13652648.1997.00371.x

Fomunyam, K.G. 2016a. Student Teachers Negotiating Teachers' Professional Identity. Journal of Educational Science 13,2: 186 - 193. https://doi.org/10.1080/09751122.2016.11890452

Fomunyam, K.G. 2016b. Theorising Student Constructions of Quality Education in a South African University. Southern African Review of Edu- 
cation with Education with Production 22,1: 46 - 63.

Fomunyam, K.G. \& T. Mnisi 2017. Temperament as a Determinant of Success in Formative Assessment in Engineering Education. International Journal of Applied Engineering Research 12,14: 4152 - 4161.

Galla, B.M., B.D. Plummer, R.E. White, D. Meketon, S.K. D'Mello \& A.L. Duckworth 2014. The Academic Diligence Task (ADT): Assessing Individual Differences in Effort on Tedious but Important Schoolwork. Contemporary Educational Psychology 39,4: 314 - 325.

https://doi.org/10.1016/j.cedpsych.2014.08.001

Giloi, S.L. 2015. The Knowledge - Knower Structures Used in the Assessment of Graphic Design Practical Work in a Multi-campus Context. PhD Full thesis, Rhodes University, Grahamstown.

Horn, L. \& A-M. Nuñez 2000. Mapping the Road to College First-generation Students' Math Track: Planning Strategies, and Context of Support. Diane Publishing.

Ishitani, T.T. 2006. Studying Attrition and Degree Completion Behavior among First-generation College Students in the United States. The Journal of Higher Education 77,5: 861 - 885.

https://doi.org/10.1353/jhe.2006.0042

Kuh, G.D., T.M. Cruce, R. Shoup, J. Kinzie \& R.M. Gonyea 2008. Unmasking the Effects of Student Engagement on First-year College Grades and Persistence. The Journal of Higher Education 79,5: 540-563.

https://doi.org/10.1080/00221546.2008.11772116

Lee, K.J., R. Dunlap \& M.B. Edwards 2014. The Implication of Bourdieu's Theory of Practice for Leisure Studies. Leisure Sciences 36,3: 314 - 323. https://doi.org/10.1080/01490400.2013.857622

Mack, N., C. Woodsong, K.M. MacQueen, G. Guest \& E. Namey 2005. Qualitative Research Methods: A Data Collectors Field Guide. North Carolina: Family Health International.

Maree, K. 2007. First Steps in Research. Pretoria: Van Schaik Publishers.

Maton, K. 2000. Languages of Legitimation: The Structuring Significance for Intellectual Fields of Strategic Knowledge Claims. British Journal of Sociology of Education 21,2: 147 - 167.

https://doi.org/10.1080/713655351

Maton, K. 2005. A Question of Autonomy: Bourdieu's Field Approach and Higher Education Policy. Journal of Education Policy 20,6: 687 - 704. https://doi.org/10.1080/02680930500238861 
Maton, K. 2013. Knowledge and Knowers: Towards a Realist Sociology of Education: Routledge. https://doi.org/10.4324/9780203885734

Morrow, W. 1993. Epistemological Access in the University. AD Issues 1,1: 3 $-4$.

Morrow, W. 1994. Entitlement and Achievement in Education. Studies in Philosophy and Education 13,1: 33 - 47. https://doi.org/10.1007/BF01074084

Morrow, W. 2007. Learning to Teach in South Africa. Pretoria: HSRC Press. Morrow, W. 2009. Bounds of Democracy: Epistemological Access in Higher Education. Pretoria: HSRC Press.

Muller, J. 2014. Every Picture Tells a Story: Epistemological Access and Knowledge. Education as Change 18,2: 255 - 269.

https://doi.org/10.1080/16823206.2014.932256

Naidoo, R. 2004. Fields and Institutional Strategy: Bourdieu on the Relationship between Higher Education, Inequality and Society. British Journal of Sociology of Education 25,4: 457 - 471.

https://doi.org/10.1080/0142569042000236952

Neuman, W.L. 2010. Social Research Methods: Quantitative and Qualitative Methods. Anthropology and Education Quarterly 3.

Palys, T. 2008. Basic Research. The Sage Encyclopedia of Qualitative Research Methods 58-60.

Powell, T.C. 2017. Strategy as Diligence: Putting Behavioral Strategy into Practice. California Management Review 59,3: 162 - 190.

https://doi.org/10.1177/0008125617707975

Putnam, R.D. 1995. Bowling Alone: America's Declining Social Capital. Journal of Democracy 6,1: 65 - 78. https://doi.org/10.1353/jod.1995.0002

Putnam, R.D. 2000. Bowling Alone: America's Declining Social Capital. Culture and Politics. Springer.

https://doi.org/10.1007/978-1-349-62397-6_12

Reay, D. 2004. 'It's all becoming a habitus': Beyond the Habitual Use of Habitus in Educational Research. British Journal of Sociology of Education 25,4: 431 - 444.

https://doi.org/10.1080/0142569042000236934

Seidman, I. 2006. Interviewing as Qualitative Research: A Guide for Researchers in Education and the Social Science. New York: Teachers College Press.

Sennett, J., G. Finchilescu, K. Gibson \& R. Strauss 2003. Adjustment of Black 
Students at a Historically White South African University. Educational Psychology 23,1: 107 - 116.

https://doi.org/10.1080/01443410303219

Shawa, L.B. 2015. Graduate Output in South African Higher Education. Paper presented at the University of KwaZulu-Natal's 9th Annual Teaching and Learning in Higher Education Conference 2015, Durban, KwaZulu-Natal, South Africa.

Strydom, F., G. Kuh \& M. Mentz 2010. Enhancing Success in South Africa's Higher Education: Measuring Student Engagement. Acta Academica 42,1: 259 - 278.

Sullivan, A. 2002. Bourdieu and Education: How Useful is Bourdieu's Theory for Researchers? Netherlands Journal of Social Sciences 38,2: 144 166.

Tinto, V. 1975. Dropout from Higher Education: A Theoretical Synthesis of Recent Research. Review of Educational Research 45,1: 89 - 125. https://doi.org/10.3102/00346543045001089

Ulate, N.V. \& O.C. Carballo 2010. Factors Contributing to the Academic Performance of BEI Learners. LETRAS 1,47: 35 - 58.

Walker, J. \& E. Yoon 2017. Becoming an Academic: The Role of Doctoral Capital in the Field of Education. Higher Education Research \& Development 36,2: 401 - 415. https://doi.org/10.1080/07294360.2016.1207616

Warwick, R., J. McCray \& D. Board 2017. Bourdieu's Habitus and Field: Implications on the Practice and Theory of Critical Action Learning. Action Learning: Research and Practice 14,2: 104 - 119. https://doi.org/10.1080/14767333.2017.1296409

Mlamuli Nkosingphile Hlatshwayo Curriculum and Education Studies College of Humanities University of KwaZulu-Natal Hlatshwayom@ukzn.ac.za

Kehdinga George Fomunyam Institute for System Sciences Durban University of Technology georgek@dut.ac.za 